\title{
The Progress of Digital Currency Electronic Payment
}

\author{
Xinyu Liu ${ }^{1, *}$, a, $\dagger$, Fan $\mathrm{Lu}^{2, *}$, b,, , Wanlu Shan ${ }^{3, *, c, \dagger}$, Jiayuan Zhang ${ }^{4, *, d, \dagger}$ \\ ${ }^{1}$ College of Business \& Public Management, Accounting, Wenzhou-Kean University, Wenzhou, China \\ ${ }^{2}$ School of Public Finance and Taxation, Shandong University of Finance and Economics, Shaoxing, China \\ ${ }^{3}$ Adam Smith School of business, University of Glasgow, Zhengzhou, China \\ ${ }^{4}$ School of Management Science and Engineering, Shandong University of Finance and Economics, Heze, China \\ "Corresponding author.Email: a1098646@wku.edu.cn, ${ }^{b} 20180214360 @$ mail.sdufe.edu.cn, \\ c2431152S@student.gla.ac.uk, djiayuan_zhang@mail.sdufe.edu.cn \\ ${ }^{+}$These authors contributed equally.
}

\begin{abstract}
Developed and issued by the People's Bank of China, the Digital Currency Electronic Payment has the same legal status as the physical RMB. This essay will describe the basic information, development, and advantages of the DCEP and the challenges and risks that may be encountered in the development, distribution, and use of the DCEP. According to the existing social information, the blueprint and future development of the DCEP is forecasted. Overall, DCEP will help improve the convenience of daily payment for Chinese residents, reduce the cost of the central bank's management of RMB, accelerate the development of the digital economy, and promote social and technological progress.
\end{abstract}

Keywords: Digital Currency, Electronic Payment, Blockchain.

\section{INTRODUCTION}

The history of the evolution of monetary forms shows that they evolve according to the needs of people. In the 1970s, Chaum's (1982) proposal for an anonymous network payment system using "blind signature" technology pioneered this area of research. In 2004, cryptographer Finney improved Back's hash algorithm into a "reusable proof-of-work mechanism"; in 2005, Szabo introduced the mechanism into digital currencies. In 2005, Szabo introduced this mechanism to the digital currency Bitgold, which successfully solved the problems of "book consistency" and "currency generation"[1]. Although this series of digital currencies all failed because they had to rely on a centralized third party to process their transactions, these attempts and experiments eventually laid the foundation for the creation of Bitcoin. With the advent of the digital economy, Dorian S. Nakamoto came up with the design idea for Bitcoin in 2008 and officially launched it the following year. The revolutionary breakthrough lies in its "distributed" and "decentralized" characteristics: the issuing body is not a state agency with the right to issue money, and the circulation does not depend on existing bank accounts and can be freely circulated among groups of people who support and trust its value.
Although cryptocurrencies such as Bitcoin are currently regarded as an investment asset, the DLT technology behind them and the "decentralization" of money that they trigger, coupled with the rapid expansion of the types and sizes of digital currencies worldwide in recent years, have led to significant changes in the modern payment system. Central banks gradually realize that both privately issued digital currencies and central bank digital currencies may become part of the monetary system in the future, so it is the consensus of central banks to strengthen the research of central bank digital currencies to ensure that they do not lag behind the wave of digital currency development.

With the gradual understanding of DCEP's background, knows the future of DCEP arouses wide world attention. Digital currency, e.g., Bitcoins, blockchain, and other emerging financial technology, has rapidly developed in recent years and affected our national sovereign currency's status. Hence, the issuance of DCEP can ensure the status of the sovereign and maintain the financial system's stability. By the way, DCEP will satisfy the need for digital currency under the internet financial system in the nowadays digital economic era. It is clear to see the future direction of DCEP's development, and the issuance of DCEP will provide enormous benefits. However, at the moment, 
China enjoys the dividends of the issuance of DCEP. They still need to withstand the pressure of moving forward and actively to the challenge. The only way to find a wider road for the issuance of DCEP is to predict audaciously and prevent prudently unknown risks and challenges.

\section{BASIC DESCRIPTIONS \& DEVELOPMENT}

\subsection{Basic descriptions}

Digital Currency Electronic Payment is the legal tender of China. It is equivalent to physical RMB, i.e., it can only be issued by the People's Bank of China (PBOC), and its effectiveness and security are the highest [2]. The PBOC issues in digital form, which anyone has the right to hold. It can be used as a retail payment instrument. There is no third party when the two sides trade [3]. Besides, the DCEP adopts a two-tier operation system, which means that the People's Bank of China will exchange the DCEP to the designated operating institutions. The operating institutions will exchange the digital RMB to the people at a $1: 1$ rate [4]. The business model is basically the same as physical RMB issuance. DCEP is based on a broad system of accounts, which means that anything that forms a person's unique identification can become a sub-wallet of the DCEP. DECP enables dual offline payments. DCEP is a video card that allows you to pay without Internet access. An ink screen window on the card immediately shows the transaction amount and balance. Figure 1 shows the "hard wallet" of DCEP. Another kind of DCEP is the electronic wallet in mobile phones. Figure 2 displays DCEP in mobile applications. DCEP supports the loose coupling of bank accounts [5]. DCEP does not require a bank card to be bound and can be paid in DCEP even without a bank account. DCEP has provided great convenience for people's life.

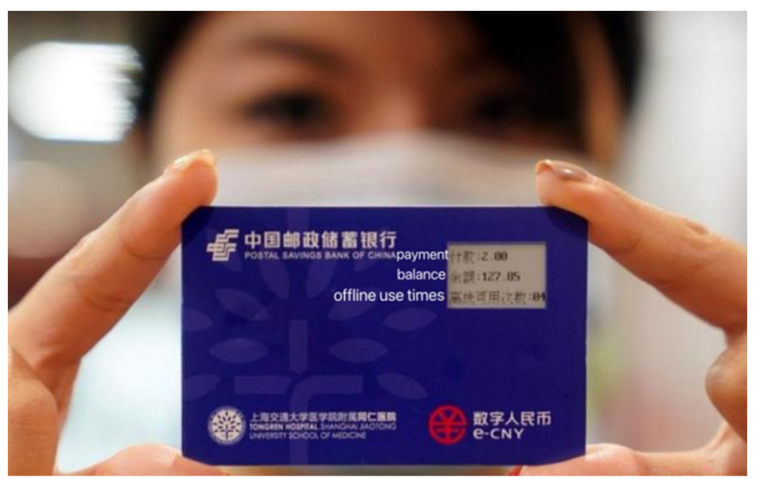

Figure 1. The first payment method of DCEP is a video card, also called a "hard wallet" [6]

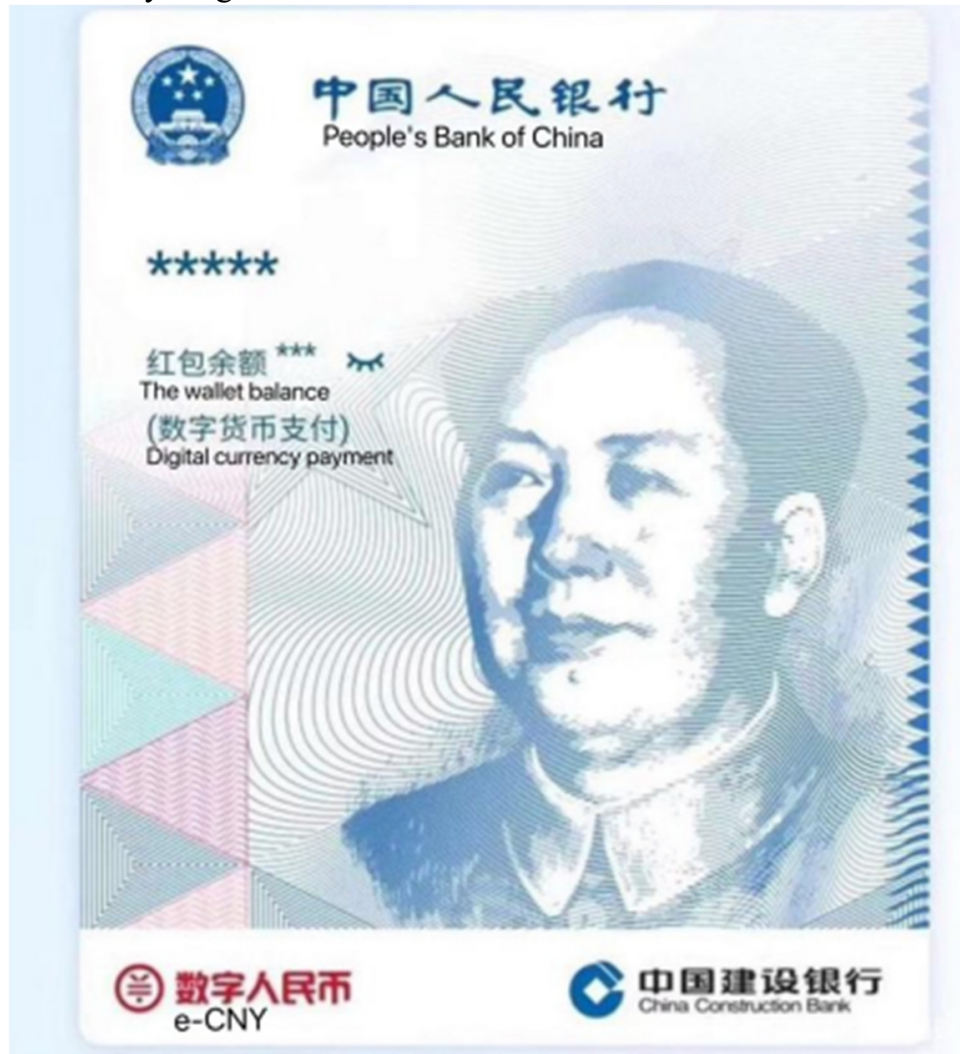

Figure 2. The second payment method of DCEP, which is what DCEP looks like in mobile application software [7] 


\subsection{Development}

With the rapid development of China's economy, the digital economy has become a major driving force in the development. The use of the digital economy is expanding, and the demand for it in remote areas is also increasing. Contemporarily, with the rapid development of mobile payment, more and more people choose to use mobile payment as a convenient and fast way, which also promotes the development of the digital economy. According to the survey, the proportion of people who use cash is decreasing [8]. However, some elderly people or people in remote areas cannot use the Internet or do not have the Internet. Hence, there is a higher demand for digital payment. Table 1 lists show the proportion of the transaction amount and value of three different mobile payment methods, cash payment, and card payment in the total amount in 2019 in China. It can be seen from Table 1 that people prefer more convenient payment methods, and the emergence of DCEP can completely replace these three payment methods and solve the problems of no network, difficulty to keep cash and card.

Table 1. The proportion of people's payment methods in 2019 [8]

\begin{tabular}{lll}
\hline & $\begin{array}{l}\text { The number of } \\
\text { transactions }\end{array}$ & $\begin{array}{l}\text { The value of } \\
\text { transactions }\end{array}$ \\
\hline Mobile payment & $66 \%$ & $59 \%$ \\
Paid in cash & $23 \%$ & $16 \%$ \\
Paid by card & $7 \%$ & $23 \%$
\end{tabular}

The People's Bank of China has attached great importance to the research and development of DCEP. In 2014, the People's Bank of China established the DCEP Research Group, which began to conduct special research on the digital currency issuance framework, key technologies, circulation environment, and relevant international experience [9]. Until January 2017, the PBOC officially established the DCEP Research Institute in Shenzhen. With the approval of the State Council, the PBOC began to cooperate with commercial institutions to develop and test digital legal tender. In November 2019, the central bank announced that the DCEP has basically completed its design and function development. In 2020, tests will be conducted in Shenzhen, Suzhou, Xiongan New Area, and Chengdu to optimize and improve [8]. In the cafeteria of Shanghai Jiao Tong University in early 2021, employees use DCEP "hard wallet" to experience payment. Unlike previous DCEP payments using mobile phones, this is the first time a hard wallet based on a video card has been unveiled [6]. So far, the People's Bank of China has conducted tests in some areas and ensured the smooth and safe operation of the trials.

\section{ADVANTAGES}

The issuance of DCEP will promote the transition of commercial banks, enhance the accuracy and effectiveness of the monetary policy, optimize the payment and settlement process, and push RMB internationalization.

As for commercial banks, DCEP can improve the efficiency of the personal retail business of commercial banks. The traceability of DCEP enables commercial banks to collect all data about the currency circulation process. In combination with the internet of things, it can help them collect all industries' indicators in real time and enrich the dimensions and accuracy of the judgments of the loan approval process [10].

In terms of the cost of cash sorting and ATM operation, commercial banks will spend more than 20 billion yuan per year [10]. Since DCEP can replace the paper money when the transaction volume is relatively small, it can reduce commercial banks' hefty storage and transfer fees, security expenses, and related equipment maintenance savings. In other words, DCEP can help commercial banks to save operating costs in daily life.

With regard to monetary policy, by replacing the currency in circulation, the money multiplier will be sensitive to the change of required deposit reserve ratio and benchmark deposit rate [11]. The central bank could adjust benchmark deposit rates and push residents to change their cash into digital currency. In this way, the destabilizing factors in the monetary transmission mechanism will decrease, and monetary policy tools can play a better role in leading enterprises, banks, and residents to change their decisions and activities properly.

On the other hand, DCEP increases the speed of currency circulation, which will vastly improve the effectiveness of monetary control. The traditional digital currency focus on the adjustment of the quantity of money supply. With the gradual promotion of DCEP, the liquidity of the financial market will increase, monetary policy will shift to interest rate-based control, the objective of policy intermediary will be more sensitive to interest rates, and the term structure of interest rate will be smoother [11]. The above changes will be conducive to the central bank to implement macro-control by using the interest rate transmission tool. 


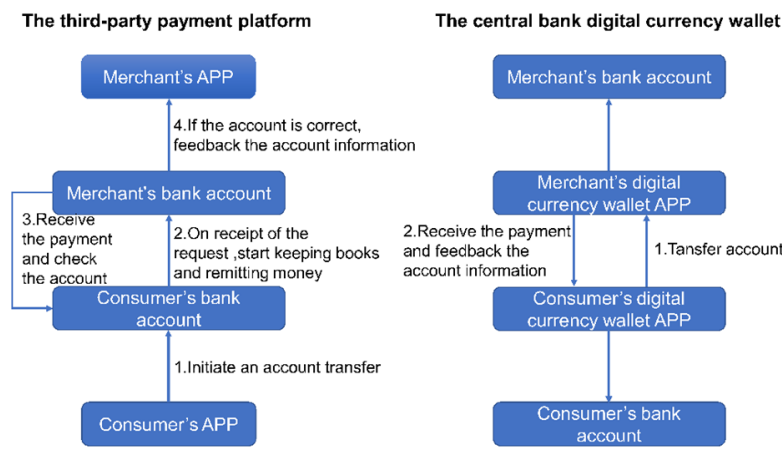

Figure 3. Two different payment and settlement processes. Translated from Ref [11]

As for the payment and settlement process, unlike Alipay and WeChat pay, DCEP does not require any charges and reduces daily life costs. Additionally, DCEP uses 'Double Offline' payment which means transactions could take place anywhere even if the consumer and merchant's devices are both unable to connect to the network.

More importantly, the payment and settlement process can be greatly simplified. Figure 3 shows two different payment and settlement processes: the thirdparty payment platform and the central bank digital currency wallet. It is obvious that the money needs to be remitted and checked in both the consumer and merchant's digital bank account. The payment and settlement process still has time-delay and cost. While for DCEP, the payment and settlement process simply takes place in their digital currency wallet and do not need to remit and check money in the digital bank account, even the devices are offline, the payment and settlement will still be made.

At present, RMB cross-border payment and settlement is mainly carried out by China International Payment System, which still needs overseas enterprises and individuals to set up an RMB deposit account. Nevertheless, as for DCEP, overseas enterprises and individuals do not need to set up a bank account if they have access to the central bank digital currency wallet. As a matter of fact, they only need to do is change the cash into digital RMB. DCEP partly expanded the scale of the use of RMB overseas and is advantageous to $\mathrm{RMB}$ internationalization.

\section{CHALLENGES \& RISKS}

The issuance and promotion of DCEP face many challenges and risks, with problems in legal regulation, digital technology, and market systems.

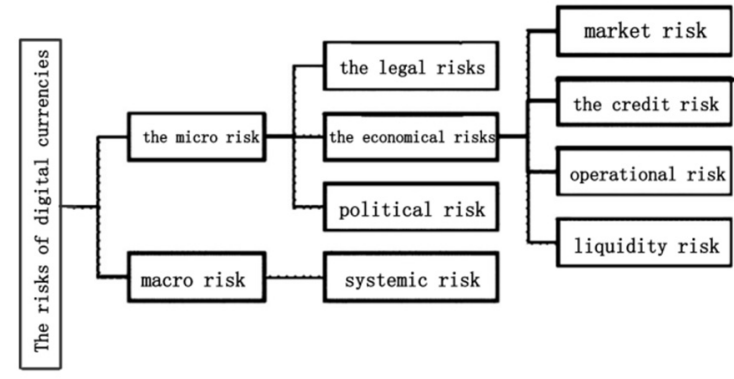

Figure 4. The risks framework to DCEP [12]

\subsection{Possible Legal and Regulatory Risks to DCEP}

Many countries do not specify whether China has the authority to issue digital currencies under the existing legal framework and whether the status of China's issuance of digital currencies is the same as that of existing currencies. As a result, digital currencies may face difficulties when circulating before different countries due to different legal regulations in different countries.

The digital currency will circulate in parallel with the traditional currency for a long time after its issuance. The current currency-related laws in China are mainly related to the traditional currency, which cannot provide legal support for the circulation and regulation of the digital currency. Moreover, the simultaneous regulation of both currencies is a huge challenge to the existing regulatory structure.

\subsection{Possible market risks for DCEP}

Libra, a foreign private digital currency led by Libra, is the same digital currency as the central bank digital currency, and there is a high substitution effect between them. Short-term treasury bonds and bank deposits back the digital currency, and its company, Facebook, has strong assets and technology strength and has nearly 2.7 billion users worldwide. Once Libra is put into global circulation, it is bound to affect the promotion of the central bank's digital currency in the international arena and even impact the domestic currency market of China and affect the sovereignty of RMB. Therefore, dealing with the relationship between foreign private digital currencies led by Libra and the central bank's digital currency is inevitable. Besides, the path to properly deal with the impact of foreign private digital currencies and avoid market risks should also be addressed [13].

\subsection{Possible operational, technical risks for DCEP}

The use of virtual currencies requires real-time monitoring of transaction data, which means that both account information and transaction data will be exposed without reservation. Balancing regulatory 
power and privacy rights will bring challenges to the protection of commercial confidentiality and personal privacy [14]. Unlike traditional currencies, virtual RMBs need to avoid anonymity when trading, and the account and personal information of each transaction will be monitored. These data will also be available to third-party registries and data analysis agencies. The conflict between privacy and personal information security, which are fundamental rights, adds difficulties to the regulation of virtual currencies.

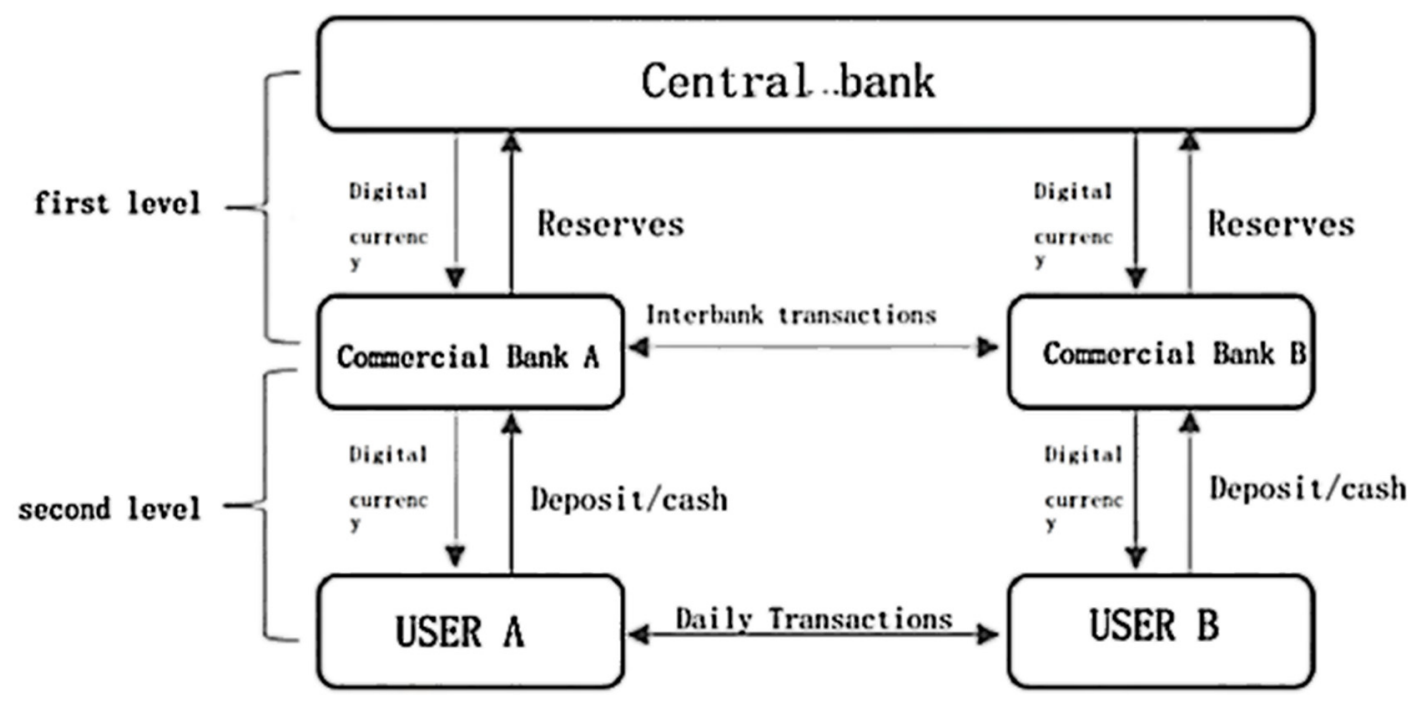

Figure 5. Two-tier operation" system [15]

\subsection{Possible technical risks to DCEP}

In some economically underdeveloped areas, there is a high probability that digital currencies without physical form will not be accepted as payment and settlement tools 。 The use of virtual currencies for transactions requires certain hardware equipment support, and virtual currencies need a longer time to really enter the market.

\subsection{Possible Systemic Risks to Digital Currencies.}

China adopts a two-tier operation mechanism of "central bank - commercial banks" to replace the currency in circulation with equivalent value, i.e., the central bank does not directly face the public but issues a certain amount of legal digital currency to commercial banks. Commercial banks are the legal digital currency business contractors, and the public can exchange their cash into the legal digital currency through commercial banks. [16] However, the two-tier operation system of digital RMB objectively requires the PBOC to build the infrastructure of payment, clearing, and settlement and develop scientific specifications to ensure the sharing and interoperability among operating institutions and to have alternative and contingency plans. Since there is no better precedent for accomplishing these tasks as a reference, accomplishing them more perfectly will become a pressure for the central bank.

Commercial banks need to use virtual currencies as a focus point to upgrade their development and adapt the infrastructure required by virtual currencies as soon as possible to minimize the operational impact of the central bank's digital currency. However, the issuance of digital RMB will undoubtedly still pose serious challenges to sectors such as commercial banks and payment institutions in the short term, creating a new impact on the existing financial system landscape.

\section{FUTURE DEVELOPMENT}

Considering the characteristics, advantages, and disadvantages of DCEP, it can be predicted that DCEP will occupy an important position in the future financial industry [17]. If DCEP completely replaces paper money for circulation, it will have a subversive impact. The weakening of the role of paper money will predictably hit the banknote printing industry and the armed escort industry. Under the impact of COVID-19, abandoning the use of paper money will help prevent the virus from spreading through contact [18].

In China, DCEP is expected to have better development. This government-supported currency will enter the lives of more Chinese people and bring new payment experiences and payment habits. In the future, in addition to mobile phones, watches, and other devices may contain DCEP chips to facilitate people's payment. Various biometric technologies, such as using fingerprints and voice, may play a role in confirming payment [18]. On the other hand, the business of China's existing mobile payment giants, including Alibaba and Tencent, may be threatened by DCEP. In 2019, mobile payment transactions accounted for fourfifths of China's total payments [19]. Whereas people 
only pay digital cash in their bank accounts through Alipay and WeChat. Mobile payment through a third party has some disadvantages, such as relying on the network and the QR code or bar code refreshed in time. Besides, existing mobile payments are often not allowed to conduct large transactions. In China, these large transactions are still carried out through traditional banks and credit cards. In this case, DCEP payment with advantages will be predictably favored by more people. Scholars predict that third-party payment instruments will eventually become the carrier of DCEP and lose their market share [18]. Meanwhile, the Chinese government will benefit from the wide use of DCEP. DCEP is more convenient for currency tracking than paper money. This will benefit the government's financial supervision. For example, tracking the source and destination of money in financial crime cases. At the same time, data obtained from DCEP is also a powerful tool for market analysis. For example, DCEP can more conveniently and quickly count people's consumption behavior. Thus, companies can gain the data to analyze the market. Perhaps this will become a new business opportunity [18]. In this case, there is no doubt that DCEP users' concerns about personal privacy will also increase. When using third-party software for mobile payment, privacy concerns have reduced people's willingness to use this payment method [20]. Perhaps DCEP can provide more secure services to prevent information disclosure by third-party companies. But people are still worried that the government will monitor their consumption.

Worldwide, the development of DCEP will bring changes to the world financial market. In the 2020 report, the World Bank Group pointed out that one-fifth of the world's banks will introduce the DCEP system in the next five years. Some experts believe that financial technology will improve the speed of transactions and investments and bring the world's digital financial system to a new level [19]. More importantly, for China, DCEP will promote the internationalization of RMB that China has always expected. Until 2020, USD payment still accounts for $40.88 \%$ of international payment, while RMB payment only accounts for $1.79 \%$. The Chinese government attempts to gradually promote DCEP internationally through how well-known international brands, such as Starbucks, use the DCEP system for retail transactions in China. In addition, China hopes to cooperate with other governments to settle cross-border transactions in RMB. Because of the shortage of dollars caused by COVID-19, the process of RMB internationalization can avoid the "dollar trap". In the future, the success of RMB internationalization may break the US dollar-centered world financial system established since World War II [19]. Multiple currency payments will provide better security and stability for world finance and reduce the impact of the possible financial crisis.

\section{CONCLUSION}

Since 2021, DCEP has gradually entered the Chinese market. In the development of DCEP, the advantages and disadvantages of this kind of digital currency are gradually recognized. To sum up, DCEP can facilitate people's daily lives and bring more possibilities for the further development of the financial industry. DCEP will help the government to regulate finance and help the internationalization of RMB. Meanwhile, external threats, technical and management factors cannot be ignored for the potential threat of DCEP. People will also worry about the impact of DCEP on personal privacy. Although the final development of DCEP is unpredictable, in general, DCEP will bring more benefits to China. In the future, DCEP will be more widely used and move from China to the world.

\section{REFERENCES}

[1] Wang X. \& Jia Y. (2020) International monetary competition in the context of digitalization and its implications for RMB internationalization[J]. Southern Finance, 2020,(05):12-21.

[2] King \& Wood M. (2021). CHINA LAW INSIGHT: China's digital RMB - is your business ready? Retrieved from:

https://translate.google.com/translate?hl=zh$\mathrm{CN} \& \mathrm{sl}=\mathrm{en} \& \mathrm{tl}=\mathrm{zh}-$

$\mathrm{CN} \& \mathrm{u}=\mathrm{https} \% 3 \mathrm{~A} \% 2 \mathrm{~F} \% 2 \mathrm{Fwww}$. chinalawinsight.c om $\% 2$ F $2021 \% 2$ F05\%2Farticles $\% 2$ Fcrossingborders $\% 2$ Fchinas-digital-rmb-is-your-businessready $\% 2 \mathrm{~F} \&$ anno $=2 \&$ prev $=$ search $\&$ sandbox $=1$

[3] Grym, A., Heikkinen, P., Kauko, K. \& Takala, K. (2017). Central bank digital currency. BoF Economics Review. Retrieved from: www.suomenpankki.fi

[4] Liu X. (2020). Analysis on the Main Characteristics and Influence of Digital RMB. People's Forum, No.681(26), 88-93.

[5] Han D \& Zhao Y. (2021) "Analysis on risks and Development Countermeasures of Central Bank digital RMB issue," 2021 International Conference on Public Management and Intelligent Society (PMIS). pp. 250-254. doi: 10.1109/PMIS52742.2021.00062.

[6] Xinhua News Agency. (2021). Digital Renminbi "Hard Wallet" is coming! Video card first unveiled. Xinhua News. Retrieved from: https://baijiahao.baidu.com/s?id=16880474425450 $10110 \& w f r=$ spider \&for $=\mathrm{pc}$

[7] Mobile payment network. (2020). View the final form of DCEP from the opening experience of 
CCB's digital RMB. Cicc's online. Available from: http://mp.cnfol.com/27131/article/1598868586139385536

[8] People's Bank of China. (2021). Progress on Research and Development of E-CNY in China. Progress of Research \& Development of E-CNY in China. Retrieved from: http://www.pbc.gov.cn/en/3688110/3688172/4157 443/4293696/2021071614584691871.pdf

[9] Liu Y. \& Shang G. (2021). The Development and Influence Analysis of Digital RMB. Financial Economics (2), 5 .

[10] Hao Y. (2019) National experience of legal digital currency development and China's commercial banks' counter measures. International Finance,2019(02):73-80.

[11] Wu T. \& Wang J.(2020). China's Central Bank Issuing Digital Currency: Impact, Problems and Countermeasures. Southwest Finance,2020(07):2537.

[12] Zhang J.(2017).Digital currency regulation under the perspective of risk management - taking bitcoin as an example. Huazhong University of Science and Technology

[13] Wu T. \& Guo J. (2019) An economic analysis of Facebook cryptocurrency Libra: background, connotation, impact and challenges. Guizhou Social Science.
[14] Zhang L. \& Xu B. (2021) Legal risks and institutional improvement of legal digital currency application. journal of Law Forum.

[15] Chen H \& Gong H.(2021).Study on the digital currency of China's central bank. Academic Exchange (2):14

[16] Fan Y. (2016) The theoretical basis and architectural options for a legal digital currency in China. China Finance.

[17] Oxford Analytical. (2021). Digital Yuan Will Affect Finance in China and Beyond. Expert Briefings. Restrieved from https://doi.org/10.1108/OXAN-DB259720

[18] Yi Z. (2020). The Impact of Central Bank Digital Currency DCEP on Future Life. Quality and market, No. 21, 2020, 136-138, 3 pages in total. Quality \&amp; Market.

[19] Michael A. P., Benjamin G. \& Haiyang (Melissa) Y. (2020). Cryptocurrencies, China's sovereign digital currency (DCEP) and the US dollar system, Educational. Philosophy and Theory, DOI: 10.1080/00131857.2020.1801146

[20] Y. Huang \& W. Liu. (2012) The Impact of Privacy Concern on Users' Usage Intention of Mobile Payment. 2012 International Conference on Information Management, Innovation Management and Industrial Engineering, 2012, pp. 90-93, doi: 10.1109/ICIII.2012.6339927. 